\title{
Algorithmic Approach to Lower Lid Blepharoplasty
}

\author{
Ryan M. Collar, MD $\quad$ Sofia Lyford-Pike, MD ${ }^{1} \quad$ Patrick Byrne, MD ${ }^{1}$ \\ ${ }^{1}$ Department of Otolaryngology Head and Neck Surgery, The Johns \\ Hopkins University School of Medicine, Baltimore, Maryland \\ Facial Plast Surg 2013;29:32-39.

\begin{abstract}
Address for correspondence and reprint requests Patrick Byrne, MD, The Johns Hopkins School of Medicine, Department of Otolaryngology, Head and Neck Surgery, Division of Facial Plastic and Reconstructive Surgery, 601 N. Caroline St., 6th Floor, Baltimore, MD 21287
\end{abstract} \\ (e-mail: pbyrne2@jhmi.edu).
}

\author{
Abstract \\ Keywords \\ - lower lid \\ blepharoplasty \\ - subciliary approach \\ - transconjunctival \\ approach \\ - lid anchoring \\ - skin-muscle flap
}

The debate continues around transconjunctival versus transcutaneous approaches. Despite the perceived safety of the former, many experienced surgeons continue to advocate the latter. This review aims to present a balanced view of each approach. It will first address the anatomic basis of lower lid aging and then organize recent literature and associated discussion into the transconjunctival and transcutaneous approaches. The integrated algorithm employed by the senior author will be presented. Finally this review will describe less mainstream suture techniques for lower lid rejuvenation and lower lid blepharoplasty complications with a focus upon lower lid malposition.
Controversy around lower lid blepharoplasty persists in aesthetic facial surgery. Popularized in the 1970s by Rees after innovation by McIndoe, the skin-muscle flap was a workhorse for lower lid blepharoplasty into the 1990s. ${ }^{1}$ It was broadly applicable, effectual, and easily performed. ${ }^{2-4}$ Despite generally good results, unsatisfactory outcomes were too often highly problematic-hallowing of the orbit, denervation atrophy of the orbicularis oculi, hallowing of the orbit, lower lid malposition, and frank ectropion. ${ }^{5-7}$ As a result, the transconjunctival approach, as introduced by Bourguet and later adapted by Tessier, gained traction in the 1990s through Zarem and Resnik. ${ }^{8-10}$ Lauded for avoiding lid malpositioning and denervation atrophy problems, this approach was employed for conventional fat resection and often combined with $\mathrm{CO}_{2}$ laser resurfacing. ${ }^{11}$ This approach conferred unique problems, including inability to redrape skin and muscle, and laser-derived hypopigmentation or scar.

Contemporary lower lid blepharoplasty has taken lessons from these eras. Supported by modern anatomic understanding of the orbitomalar sulcus deformity, ${ }^{12-14}$ current literature describes targeted maneuvers aimed to smooth the lidcheek junction. These techniques include release of retaining ligaments, ${ }^{15-18}$ fat transposition, ${ }^{19-22}$ and midface volume augmentation. ${ }^{23-29}$ Meanwhile, risk abating principles of conservative fat excision and various lid-anchoring procedures have come to the forefront. ${ }^{30-32}$
This said, the debate continues around transconjunctival versus transcutaneous approaches. Despite the perceived safety of the former, many experienced surgeons continue to advocate the latter. This review chapter aims to present a balanced view of each approach. It will first address the anatomic basis of lower lid aging, and then organize recent literature and associated discussion into the transconjunctival and transcutaneous approaches. The integrated algorithm employed by the senior author will be presented. Finally this review will describe less mainstream suture techniques for lower lid rejuvenation and lower lid blepharoplasty complications with focus upon lower lid malposition.

\section{The Aging Lower Lid, Anatomical Considerations}

\section{Eyelid Anatomy}

Fundamental to the youthful lower eyelid is its smooth surface contour from the lid margin to midface without shadow formation. Multiple anatomic factors and relationships contribute to this aesthetic.

The skin of the lower eyelid is the thinnest of the body. It overlies scant subcutaneous fat. It transitions to thicker skin in the cheek. In youth, it is free of actinic changes, fine rhytids, and there is no excess.
Issue Theme Aesthetic Treatment of the Eyelids and Midface; Guest Editors, Michael M. Kim, MD, and Tom D. Wang, MD, FACS
Copyright $\odot 2013$ by Thieme Medical Publishers, Inc., 333 Seventh Avenue, New York, NY 10001, USA. Tel: +1(212) 584-4662. 


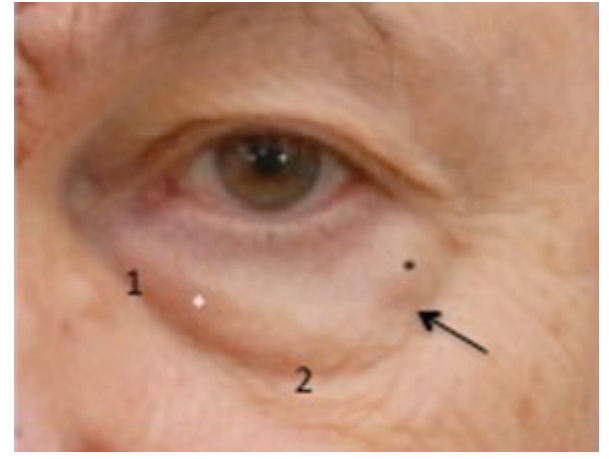

Fig. 1 Surface anatomy, lower lid. 1, tear trough deformity; 2, lid-cheek junction; black asterisk, lateral fat compartment; white asterisk, central fat compartment; arrow, condensation of Lockwood's ligament.

The orbicularis oculi is deep to the skin. ${ }^{33}$ It is divided into three parts: pretarsal, preseptal (or palpebral), and orbital. The palpebral orbicularis oculi associates medially with the medial palpebral ligament and laterally with the skin and lateral orbital tubercle. The orbital orbicularis oculi fibers orient circularly about the orbit. They originate from the medial palpebral ligament, frontal process of the maxilla, and inferomedial orbital rim. In the deep lateral plane, a ligamentous attachment, the orbital retaining ligament (ORL), attaches the orbital orbicularis to the periosteum of the maxilla. ${ }^{12,13,34}$ The youthful lid has a short vertical height, as the orbicularis complex is without laxity or redundancy and has good tone.

Posterior to the orbicularis oculi is the orbital septum, a connective tissue partition of the anterior orbit. The arcus marginalis is the confluence of the orbital septum attaching to the bony orbital rim. The orbital fat is maintained within the orbit by the orbital septum. Fat is subdivided into medial, central, and lateral compartments by the inferior oblique muscle and a condensation of Lockwood's ligament, respectively (-Fig. 1). ${ }^{35}$ In youth, the orbital septum and Lockwood's suspensory ligament are tight, together maintaining orbital fat posterior to a vector connecting the lid margin and the orbital rim.

Inferiorly the malar fat pad of the cheek is in the subcutaneous compartment. In the youthful face, its superior border extends over the orbital rim and inferior aspect of the orbital orbicularis oculi muscle. This overlapping soft tissue coverage upon the orbital rim is essential to a smoothly contoured transition from eyelid to cheek.

\section{Effects of Aging on the Lower Eyelid}

With aging, the critical finding is a demarcation of the cheek from the eyelid, with resultant shadows cast along adjacent convexities. In essence, lower lid aging may be considered as two convexities separated by a sulcus.

\section{The Upper Convexity}

Pseudoherniation of orbital fat comprises the upper convexity. Causal theories include increased laxity of the orbital septum itself and/or weakening of Lockwood's suspensory ligament. The latter leads to inferior globe descent within the confines of the bony orbit, resulting in an anterior fat volume shift through the path of least resistance, the orbital septum. The result is pseudoherniation through an intact orbital septum allowing fat to escape anterior to a vector connecting the lid margin and orbital rim. ${ }^{22,36}$

\section{The Lower Convexity}

Displacement of the malar fat pad from the infraorbital rim creates the inferior convexity. ${ }^{34}$ This subcutaneous fat pad is subject to lipoatrophy and gravitational descent with aging that leads to an inferior migration. The result is loss of supple soft tissue coverage over the orbital rim, and a second convexity inferior to the pseudoherniation of fat.

\section{The Sulcus}

The sulcus is like a belt that separates the protruding bulge from above from the descending bulge below. The anatomy of this demarcation, or sulcus, has been the focus of recent investigation, as its clinical importance is clear (i.e., releasing the sulcus structures may allow one to more effectively blend the demarcation). The medial tear trough deformity and the lateral lid-cheek junction each have specific anatomic correlates that may be targeted with surgical rejuvenation (- Fig. 1).

Medially, the tear trough, or nasojugal groove, is the area of natural depression extending inferolaterally from the medial canthus to the midpupillary line. ${ }^{12,30}$ Recent studies demonstrate that the tear trough is specifically related to the dense connection between the palpebral orbicularis and the maxilla where it takes origin. Hence, any superior convexity (i.e., pseudoherniation of fat) is accentuated at this point of dense connection. $^{12}$

The sulcus found lateral to the tear trough is the termed the lid-cheek junction, or palpebromalar groove. In the subcutaneous plane, this area is contiguous with the nasojugal groove. ${ }^{12}$ However, in the suborbicularis plane the lid-cheek junction is marked by the presence of the ORL. Unlike the tear trough where the orbicularis takes origin with direct dense bony attachments, centrally and laterally, it is attached to the maxilla by this circumferential ligamentous structure, the ORL. ${ }^{12}$ This structure is not only important to the demarcation of the lid from the cheek (as described previously) but its release may also improve redraping of the skin-muscle flap. ${ }^{12,33,37,38}$

Skin changes include thinning, loss of elasticity, hyperpigmentation, and actinic changes, as well as increased laxity of the orbicularis oculi; all are well-described, critical features of lower lid aging. ${ }^{39}$

\section{The Transconjunctival Approach}

\section{Technique}

The steps of the transconjunctival technique have been described elsewhere. ${ }^{10}$ In brief, the surgeon anesthetizes the fornix with a small volume of $1 \%$ lidocaine with 1:100,000 epinephrine. This practice prefers the preseptal approach. The surgeon makes an incision with electrocautery between the tarsal plate and the first vascular arcade stopping lateral to the medial punctum. The lower lid retractors are 


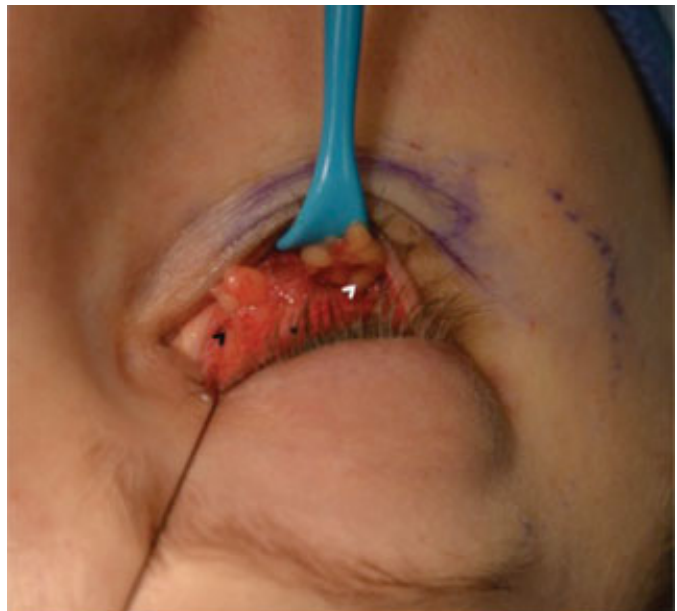

Fig. 2 Transconjunctival blepharoplasty. Inferior oblique (asterisk) separating the medial (black arrowhead) from the central fat pad (white arrowhead).

divided. The flap is elevated deep to the orbicularis oculi and superficial to the orbital septum to the level of the orbital rim. The septum may be transgressed to access preaponeurotic fat if conservative excision is planned. The inferior oblique located between the medial and central compartments is respected during the postseptal dissection (-Fig. 2). From this exposure the surgeon may perform fat transposition, or release the ORL and malar-orbicularis attachments (-Fig. $\mathbf{3}$ ).

\section{Applications and Outcomes}

The traditional and widely accepted indication for transconjunctival blepharoplasty is the treatment of mild to moderate pseudoherniation of fat in the young patient with minimal excess skin. However, recent literature embraces an expanding inventory of applications. This is likely due to the perceived advantageous safety profile with respect to lid malposition and improved understanding of the anatomy of lower lid aging that allows directed less invasive maneuvers.

\section{ORL Release and Fat Transposition}

In patients with untoward lid-cheek junction, or palpebromalar sulcus, and deep tear trough deformity, the ORL and medial orbicularis oculi attachments may be released easily through this approach. ${ }^{12-15}$ As discussed, the former anatomic entity defines the lateral lid-cheek junction, and the latter defines the medial orbitomalar sulcus (i.e., the tear trough). Through releasing these fibrous attachments, the cephalad convexity (pseudoherniated fat) can be aptly blended into the lower one (the malar-cheek mound).

Through the ORL and orbicularis releases, fat transposition, as originally described by Loeb and later Hamra, may be employed via the transconjunctival approach to specifically recontour the tear trough and lid-cheek junction with excellent reported results. ${ }^{17,19-22}$ This method highlights the modern principle of fat preservation. In this technique, the orbital septum is transgressed and preseptal fat released. Preperiosteal or postperiosteal pockets are created overlying the malar bone with blunt dissection while respecting the infraorbital nerve. Using temporary transcutaneous mattress sutures, the fat is delivered and secured into a position over the orbital rim to smooth the orbitomalar sulcus. A suborbicularis oculi fat (SOOF)-lift is easily added to this technique..$^{26,27}$

\section{Autologous Fat Transfer}

Yeh and Williams and others have reported experiences with autologous fat transfer as an adjunct to transconjunctival blepharoplasty. ${ }^{16,17,28}$ This approach is ideal for patients presenting with midfacial lipoatrophy, malar fat pad descent, and malar bony atrophy. In this scenario, fat is conservatively excised (or repositioned) via the transconjunctival approach, followed by targeted autologous fat injections (harvested and prepared via Coleman's description) along the orbital rim, malar eminence, and zygoma to obliterate the "double convexity," smooth the lid-cheek junction, and shorten the vertical height of the lid. ${ }^{40}$ Fat survial after transfer is variable and retreatment may be required. This approach has yielded admirable reported results with minimal complications.

\section{The Skin Pinch}

Patients with moderate skin excess may be treated with the transconjunctival approach plus an adjunct skin excision (i.e., a "skin pinch"). The skin pinch is a time-tested technique with modest complication rates. ${ }^{41}$ It has the advantage of no skin undermining, theoretically inciting less contraction. When

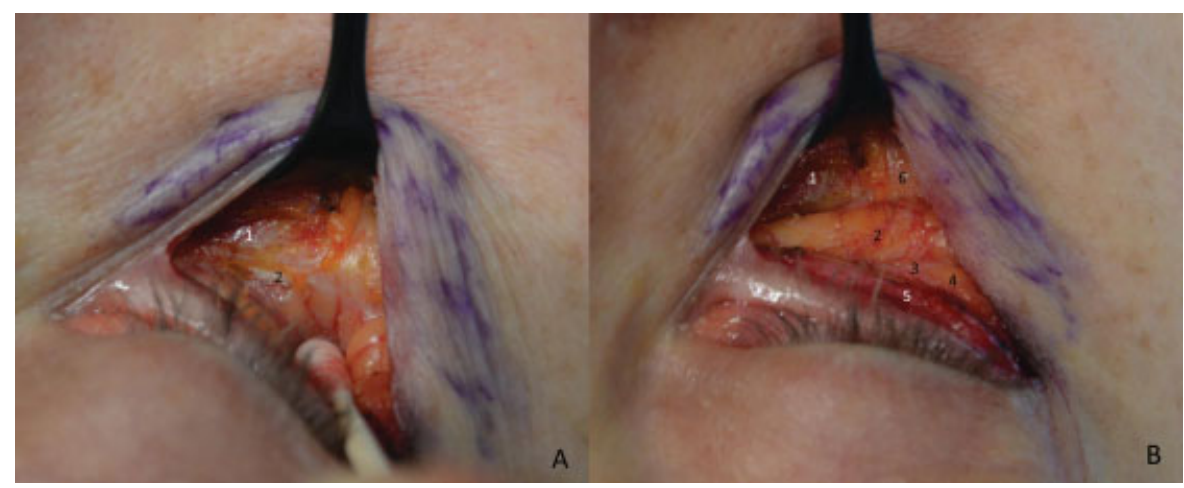

Fig. 3 Skin-muscle flap approach. (A) 1, malar orbicularis attachment; 2, orbital rim and arcuate eminence; cotton tip applicator retracting the central fat pad. (B) 1, orbicularis oculi adjacent to malar attachment; 2, central fat pad; 3, arcuate expansion of Lockwood suspensory ligament; 4 , lateral fat pad; 5 , pretarsal orbicularis; 6 , orbital retaining ligament. 
combined with fat excision, laser resurfacing, and sometimes fat transfer, good to excellent results were judged in $94 \%$ of patients, without a case of lid malposition in a recent series by Kim and Bucky. ${ }^{41}$

\section{Multimodality Approaches}

Rohrich et al recently reported their experience with the transconjunctival approach as part a five-step blepharoplasty. ${ }^{16}$ Steps include: (1) malar fat transfer, (2) transconjunctival fat excision (conservative), (3) ORL release, (4) lateral canthopexy, and (5) skin pinch excision. Computer imaging allowed measurements of pupil to eyelid margin, pupil to tear trough, tear trough width, and intercanthal angles. Conservatism led to satisfactory results in the above end points without major complications in 100 consecutive blepharoplasties.

Hidalgo similarly describes a stepwise approach to management, the cornerstone of which is the transconjunctival approach. ${ }^{17}$ Through this stepwise approach, the authors report excellent results with a $2.4 \%$ revision rate. There were three cases of lower lid malposition in the series of 248 cases.

\section{Conclusions}

Recent literature explores the transconjunctival approach in conjunction with additional targeted maneuvers to balance safety and efficacy. Nonetheless, despite expanding application, the major limitation of the transconjunctival approach remains the treatment of excess skin and muscle that requires redraping to achieve youthful contour. Further, there remains a cohort of experienced surgeons who advocate the transcutaneous approach dismissing the prevailing notion that the skin-muscle flap carries significant risk of untoward aesthetic results.

\section{Transcutaneous Approach}

\section{Technique}

The transcutaneous skin-muscle flap technique is defined elsewhere. ${ }^{1}$ In brief, an incision is made $2 \mathrm{~mm}$ below the lateral lash line into the lateral crow's-feet. Scissors are used to develop a subcutaneous dissection plane immediately below the lash line along the length of the lid. The skin is transected sharply $2 \mathrm{~mm}$ below the lash line to the level of the medial punctum. Suborbicularis dissection then ensues several millimeters inferior to the skin incision. Initial subcutaneous dissection preserves a tarsofascial sling (including pretarsal orbicularis) important for lower lid support and spontaneous blink. The plane of dissection continues immediately superficial to the thin orbital septum to the level of the orbital rim. The septum may be transgressed for fat excision if indicated. A video is available online demonstrating the medial and central fat pads and the intervening condensation of Lockwood's suspensory ligament ( removal and other maneuvers are complete, the skin and muscle are redraped, and conservative skin excision is performed. The jaw may be opened to guide the amount of excision. A lid anchoring procedure may be performed.

\section{Video 1}

The arcuate expansion, a fascial band extending from the capsulopalpebral ligament, is demonstrated separating the central and lateral fat compartments during a transcutaneous lower lid blepharoplasty.

Online content including video sequences viewable at: www.thieme-connect.com/ejournals/html/10.1055/ s-0033-1333836

\section{Applications and Outcomes}

The chief advantage of this approach is the capacity to treat excess skin and muscle that requires redraping for adequate lid recontouring. It also allows for broad exposure for wide release of the ORL, ${ }^{15}$ fat transposition, or septal reset, ${ }^{18,20}$ as well as a myriad of midface-lift procedures. ${ }^{23,24,26,27}$ Notable disadvantages include its perceived propensity for lower lid malposition, reported in the 15 to $20 \%$ range; ${ }^{5}$ orbicularis denervation atrophy; and frank ectropion, with reported rate of $1 \%{ }^{6,7}$

\section{Septal Reset}

Early efforts to correct the anatomic underpinnings of the orbitomalar sulcus include those of Hamra. Expanding on the work of Loeb, ${ }^{19}$ Hamra popularized the arcus marginalis release and transposition of orbital fat as previously described. ${ }^{20}$ This technique has since been described in various iterations by many authors, ${ }^{18,22,42}$ including its execution through transconjunctival exposure.

Hamra later described a new derivative of the fat transposition procedure, the septal reset procedure plus zygo-orbicular midface-lift. ${ }^{25}$ In this technique the midface-lift is executed in superomedial direction to shorten the vertical height of the lower lid, and the septum itself is advanced onto the malar eminence after release of the arcus marginalis to eliminate the double convexity. Impressive results were reported, but this technique failed to gain the same traction that the fat transposition technique attained, probably due to fear of lid malposition caused by middle lamellar scar contracture. That said, Barton et al recently reported on this technique highlighting the importance of broad ORL release. ${ }^{18}$ This approach was applied to 71 patients with the "tear trough triad" of pseudoherniation of fat, sharp lid-cheek junction, and retrusion of the orbital rim causing a negative vector. The authors reported excellent results, with 1 of 59 patients developing symptomatic lower lid malpositioning.

\section{SOOF-lift}

SOOF-lift is easily performed through the open skin-muscle flap approach. ${ }^{26,27}$ The SOOF is exposed deep to the orbicularis oculi upon releasing the ORL. Care is taken to preserve a cuff of periosteum at the orbital rim. The SOOF is easily elevated and secured to the orbital rim. Hence the SOOF adds volume overlying the rim to smooth the lid-cheek junction and tear trough deformity. It may be performed in conjunction with fat transposition. ${ }^{26,27}$ A video is available online demonstrating 


\section{Video 2}

Appearance of a completed suborbicularis oculi fat-lift performed through a skin-muscle flap approach in a patient with severe tear trough deformity.

Online content including video sequences viewable at: www.thieme-connect.com/ejournals/html/10.1055/ s-0033-1333836

the appearance of a completed SOOF-lift completed through a skin-muscle flap approach in a patient with severe tear trough deformity ( - Video 2).

\section{Traditional Lower Lid Blepharoplasty}

Many experienced surgeons continue to advocate the traditional lower lid blepharoplasty without additional fat repositioning or transfer, ORL release, or midface-lifting. This cohort reports excellent results with minimal complications though simple skin-muscle flap elevation, fat excision, and skin redraping alone. Maffi et al published a series of 2,007 traditional lower lid blepharoplasty procedures without lower lid anchoring procedures with reported excellent aesthetic results and a vanishingly small number of lid malposition complications ( 8 of 2,007 , or $0.04 \%) .{ }^{43}$ It should be noted that the authors excluded all patients with greater than $6 \mathrm{~mm}$ of preoperative distraction, and that other groups have questioned its overall methodology. ${ }^{44}$ Similar to Maffi et al, Garcia and McCollough also recently reported low complication rates with traditional blepharoplasty in an article subtitled "a shift-resisting paradigm" wherein lid tightening procedures are not reported. ${ }^{43,45}$

\section{Conclusion}

The skin-muscle flap is a time-tested technique that is optimal for redraping lower eyelids with significant excess skin and muscle tissue to achieve youthful contour void of shadowing. It allows superlative exposure for fat transposition, ORL release, and midface-lift procedures. Experienced surgeons posit its safety and efficacy through large series over decades of practice, a suggestion in and of itself that this technique delivers results that derive patient satisfaction.

\section{Algorithm}

Taken together there are conflicting opinions around the optimal approach to lower lid blepharoplasty. With complication rates ranging from 0.4 to $20 \%$ for the skin-muscle flap, aesthetic results remaining largely subjective, and the confounding variability of patient selection and surgeon acumen across reports, it is challenging, if not impossible, to make a universal claim for one approach over another. By drawing upon the lessons of the reported series and this practice's accumulated experience, we have developed an integrated approach to lower lid rejuvenation that relies on both transconjunctival and skin-muscle flap approaches (-Fig. 4).

The principal algorithm decision is admittedly subjective. The determination of significant excess skin and muscle relies on a gestalt assessment of the appearance and tactile properties of the lower lid. Lower lids that have significant, heavy soft tissue felt to be comprised of both skin and muscle undergo a skin-muscle flap approach (-Fig. 5). For this patient population, the next determining factor is the degree of tear trough deformity in conjunction with skin thickness. Very thin skin is a contraindication to fat transposition to

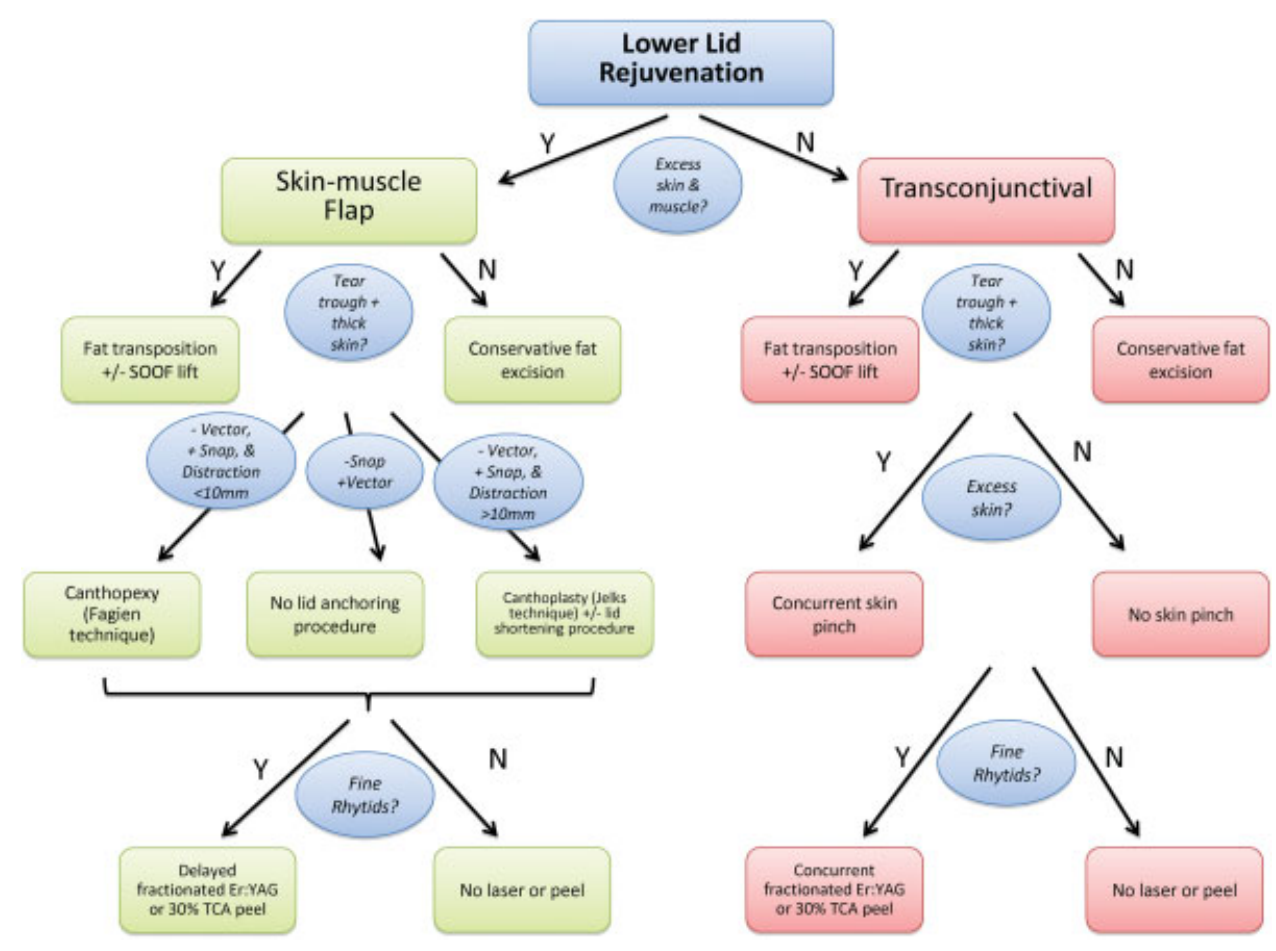

Fig. 4 Algorithm for lower lid rejuvenation. Er-YAG, erbium-doped yttrium aluminum garnet; SOOF, suborbicularis oculi fat; TCA, trichloroacetic acid. 


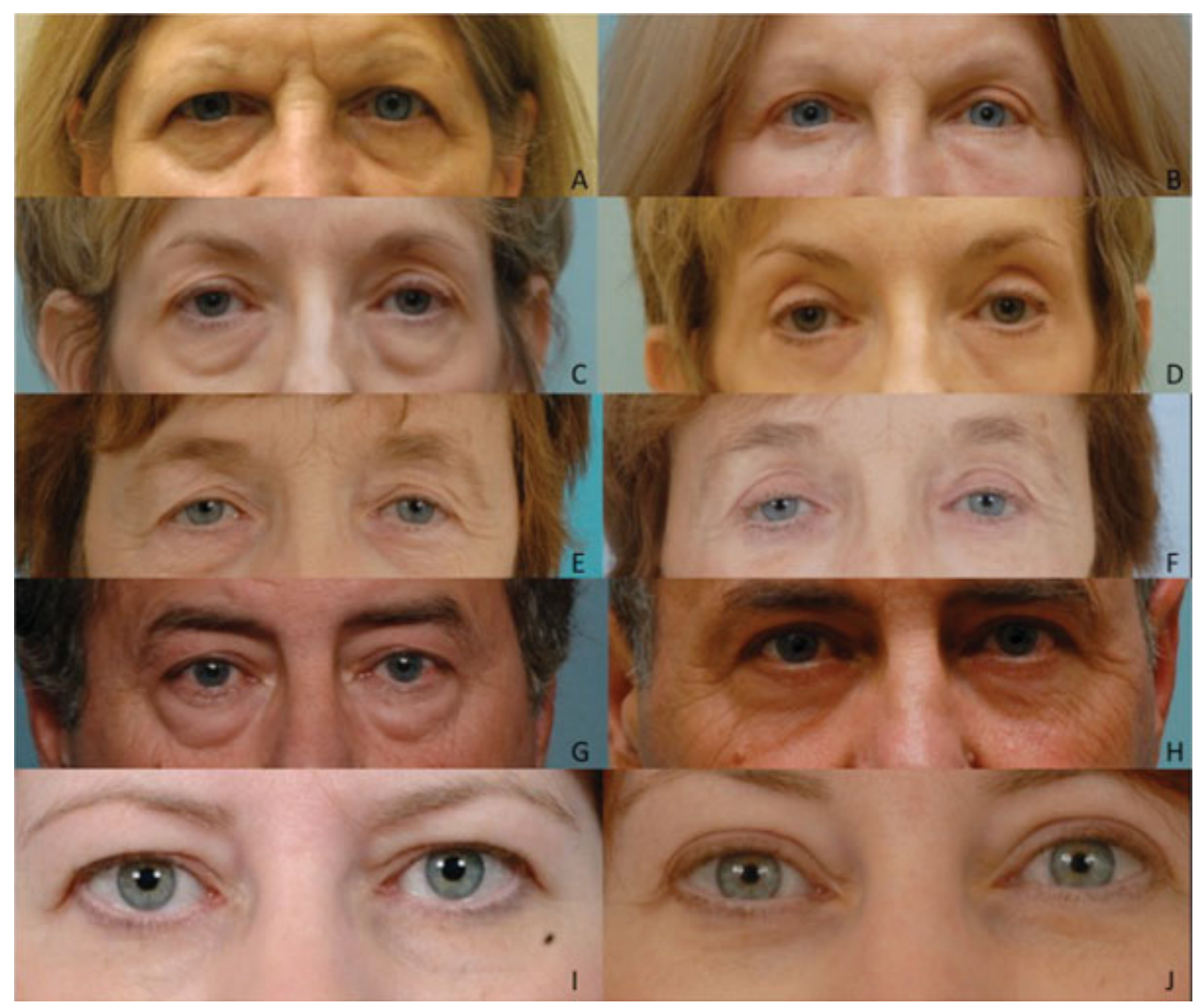

Fig. 5 Before (A) and after (B) skin-muscle flap approach with fat transposition and canthopexy for patient with excess skin and muscle, deep tear trough deformity with thick skin, and positive snap test. Before (C) and after (D) skin-muscle flap approach alone in patient with excess skin and muscle, deep tear trough but thin skin and negative snap test, minimal lower lid distraction, and positive vector. Before (E) and after (F) skinmuscle flap for patient with excess skin and muscle, no significant tear trough deformity, positive vector, negative snap test, and minimal distraction. Fine wrinkling present, deferred trichloroacetic acid (TCA) peel offered but declined. Before (G) and after (H) transconjunctival approach with fat transposition and skin pinch in patient with pseudoherniation of fat, excess skin, and deep tear trough with thick skin. Before (I) and after (J) transconjunctival approach for conservative fat excision in patient with modest pseudoherniation of fat without excess skin, deep tear trough deformity, or fine wrinkling.

avoid contour irregularities. Patients receiving fat transposition routinely undergo release of the ORL and malar orbicularis attachments. Patients at high risk for lower lid malposition in the transcutaneous group receive either canthopexy or canthoplasty, and low-risk patients receive no anchoring (-Fig. 5). ${ }^{31,32}$

For patients without excess skin and muscle, transconjunctival blepharoplasty is performed. Fat transposition, skin pinch, and erbium-doped yttrium aluminum garnet fractionated laser or 30\% trichloroacetic acid (TCA) peel are systematically utilized (-Fig. 5).

\section{Hernia Repairs}

Hernia repair suture techniques represent a somewhat unique category. Recent anatomic studies propose that pseudoherniation of fat is due to progressive laxity of Lockwood's suspensory ligament leading to descent of the globe and subsequent bulging of prepalpebral fat. ${ }^{46}$ This partially explains the hallowing of the orbit seen with excessive fat resection. To the contrary, de la Plaza and Arroyo innovatively proposed a fat-preserving capsulopalpebral fascia hernia repair procedure. ${ }^{47}$ This technique has been reported through both a transconjunctival and transcutaneous approach. ${ }^{48,49}$ In this technique, the orbital septum is opened, fat returned to the preseptal space, and the capsulopalpebral fascia is isolated and secured to the orbital rim to repair the hernia. In a rare split-face study with 11.3 years follow-up, significantly greater recurrence of fat pseudoherniation was identified on the traditional blepharoplasty side than the hernia repair side. ${ }^{49}$ Mendelson reported only one recurrence due to fat excess in over 300 cases. $^{50}$ This approach has been slow to gain mainstream application due to perceived risk of middle lamella contraction, however, Camirand et al reported 46 cases without lid malpositioning complications. ${ }^{51}$ The senior author does not employ this technique.

\section{Complications}

\section{Lower Lid Malposition}

Risk assessment, prevention, and management of lower lid malposition complications are essential to successful lid blepharoplasty surgery.

Assessing preoperative risk is paramount. Snap and distraction testing establish the degree of lower lid laxity. A snap test is deemed positive if the lower lid recoils to globe 
apposition from an inferiorly distracted position over greater than 1 second. The distraction test measures the distance the examiner may digitally anteriorize the lower lid from the globe. Hertel measurements determine eye position relative to the lateral rim. A Hertel measurement of $15 \mathrm{~mm}$ or less corresponds to deep set eyes, whereas greater than $18 \mathrm{~mm}$ suggests prominent eyes. ${ }^{52}$ The eyelid vector, or the relative position of the anterior globe to the orbital rim, should be also determined.

There is no prevailing indication for lower lid anchoring procedures. However, those patients at greatest risk include those with a positive snap test, distraction greater than $10 \mathrm{~mm}$, Hertel measurement greater than $18 \mathrm{~mm}$, and a negative vector. ${ }^{52}$ Some authors advocate routine lid tightening procedures in all cases, ${ }^{30,32}$ even transconjunctival approaches, ${ }^{16}$ whereas others do not routinely perform lid anchoring procedures with transcutaneous cases. ${ }^{43,45}$

Many lid anchoring techniques exist, ranging from canthopexy to canthoplasty, ${ }^{31,32}$ and others. ${ }^{18,52}$ One may base the anchoring point along the lateral rim upon the globe position. To avoid clotheslining the prominent globe, a high point (above inferior pupil) is selected for these negative vector patients; whereas for the deep set eye, a lower anchoring point is selected to diminish risk of squinty eye deformity in these positive vector patients. ${ }^{52}$ The important orbicularis electromyographic work of DiFrancesco et al supports the importance of canthal anchoring in transcutaneous blepharoplasty. ${ }^{53}$

Lower lid retraction as a result of overzealous lower lid blepharoplasty is difficult to treat. Treatment may involve massage, taping, and blinking exercises for mild cases, and canthoplasty, posterior lamella mucosal spacer grafting, release of capsulopalpebral fascial contracture, and midfacelifting for severe cases. A thoughtful algorithm for repair of lid malpositioning is reported by Patipa. ${ }^{53}$

\section{Other Complications}

In the immediate postoperative period, the most feared complication is retrobulbar hemorrhage $(0.04 \%)$, which requires prompt lateral canthotomy and cantholysis. Corneal abrasion is diagnosed clinically and with cobalt blue light after fluorescein placement. Treatment includes antibiotic drops four times daily, and symptoms tend to resolve within 24 hours. Other complications in the immediate postoperative setting include eyelid hematoma, infection, and eyelid sloughing. ${ }^{54}$ Chemosis occurs in $11.5 \%$ of patients undergoing lower lid blepharoplasty. It can range from minor transudative edema to extensive chemosis disabling eyelid closure and causing eyelid malposition. Median duration overall is 4 weeks, with a range of 1 to 12 weeks. Treatment includes liberal lubrication; ophthalmic steroid preparations; ocular decongestants; eye patches; and, in severe chronic cases, drainage, conjunctivotomy, and temporary tarsorhaphy. ${ }^{55}$

Complications in the intermediate stage include corneal exposure, lacrimal system dysfunction, and extraocular muscle damage. The latter typically involves the inferior oblique related to deep forniceal incision or cauterization injury. Late complications include dry eye syndrome, eyelid malposition, and malar festoons. Patients predisposed to fluid accumulation should be warned about malar festooning preoperatively and receive intraoperative steroids, postoperative steroids, and diuretics. Furosemide initiated in the early postoperative period can be replaced with a milder diuretic over time. ${ }^{54}$

\section{Conclusion}

The myriad of philosophies and surgical techniques for lower lid rejuvenation speaks to the complexity of the endeavor itself. In the end, the goals of all approaches are the same: namely, to smooth the lid-cheek junction and restore youthful contour and volume while minimizing risk. An integrated approach to lower lid rejuvenation employing both transconjunctival and skin-muscle flap techniques is presented.

\section{References}

1 Rees TD, Dupuis CC. Baggy eyelids in young adults. Plast Reconstr Surg 1969;43:381-387

2 Aston SJ. Skin-muscle flap lower lid blepharoplasty. Clin Plast Surg 1988;15:305-308

3 Casson P, Siebert J. Lower lid blepharoplasty with skin flap and muscle split. Clin Plast Surg 1988;15:299-304

4 Rees TD, Tabbal N. Lower blepharoplasty with emphasis on the orbicularis muscle. Clin Plast Surg 1981;8:643-662

5 Baylis HI, Long JA, Groth MJ. Transconjunctival lower eyelid blepharoplasty. Technique and complications. Ophthalmology 1989;96:1027-1032

6 McGraw BL, Adamson PA. Postblepharoplasty ectropion. Prevention and management. Arch Otolaryngol Head Neck Surg 1991;117:852-856

7 McCord CD Jr, Ellis DS. The correction of lower lid malposition following lower lid blepharoplasty. Plast Reconstr Surg 1993;92: 1068-1072

8 Bourguet J. Les hernies graisseuses de l'orbite: Notre traitement chirurgical. Bull Acad Natl Med 1924;92:1270-1272

9 Tessier P. The conjunctival approach to the orbital floor and maxilla in congenital malformation and trauma. J Maxillofac Surg 1973;1:3-8

10 Zarem HA, Resnick JI. Expanded applications for transconjunctival lower lid blepharoplasty. Plast Reconstr Surg 1991;88:215-220, discussion 221

11 Roberts TL III. Laser blepharoplasty and laser resurfacing of the periorbital area. Clin Plast Surg 1998;25:95-108

12 Haddock NT, Saadeh PB, Boutros S, Thorne CH. The tear trough and lid/cheek junction: anatomy and implications for surgical correction. Plast Reconstr Surg 2009;123:1332-1340, discussion 1341-1342

13 Goldberg RA, McCann JD, Fiaschetti D, Ben Simon GJ. What causes eyelid bags? Analysis of 114 consecutive patients. Plast Reconstr Surg 2005;115:1395-1402, discussion 1403-1404

14 Stutman RL, Codner MA. Tear trough deformity: review of anatomy and treatment options. Aesthet Surg J 2012;32:426-440

15 Schiller JD. Lysis of the orbicularis retaining ligament and orbicularis oculi insertion: a powerful modality for lower eyelid and cheek rejuvenation. Plast Reconstr Surg 2012;129:692e-700e

16 Rohrich RJ, Ghavami A, Mojallal A. The five-step lower blepharoplasty: blending the eyelid-cheek junction. Plast Reconstr Surg 2011;128:775-783

17 Hidalgo DA. An integrated approach to lower blepharoplasty. Plast Reconstr Surg 2011;127:386-395

18 Barton FE Jr, Ha R, Awada M. Fat extrusion and septal reset in patients with the tear trough triad: a critical appraisal. Plast Reconstr Surg 2004;113:2115-2121, discussion 2122-2123 
19 Loeb R. Fat pad sliding and fat grafting for leveling lid depressions. Clin Plast Surg 1981;8:757-776

20 Hamra ST. Arcus marginalis release and orbital fat preservation in midface rejuvenation. Plast Reconstr Surg 1995;96:354-362

21 Massry GG, Hartstein ME. The lift and fill lower blepharoplasty. Ophthal Plast Reconstr Surg 2012;28:213-218

22 Baker SR. Orbital fat preservation in lower-lid blepharoplasty. Arch Facial Plast Surg 1999;1:33-37

23 Patipa M. Transblepharoplasty lower eyelid and midface rejuvenation: part I. Avoiding complications by utilizing lessons learned from the treatment of complications. Plast Reconstr Surg 2004;113:1459-1468, discussion 1475-1477

24 Patipa M. Transblepharoplasty lower eyelid and midface rejuvenation: part II. Functional applications of midface elevation. Plast Reconstr Surg 2004;113:1469-1474, discussion 1475-1477

25 Hamra ST. The role of the septal reset in creating a youthful eyelidcheek complex in facial rejuvenation. Plast Reconstr Surg 2004; 113:2124-2141, discussion 2142-2144

26 Freeman MS. Transconjunctival sub-orbicularis oculi fat (SOOF) pad lift blepharoplasty: a new technique for the effacement of nasojugal deformity. Arch Facial Plast Surg 2000;2:16-21

27 Atiyeh BS, Hayek SN. Combined arcus marginalis release, preseptal orbicularis muscle sling, and SOOF plication for midfacial rejuvenation. Aesthetic Plast Surg 2004;28:197-202

28 Yeh CC, Williams EF III. Fat management in lower lid blepharoplasty. Facial Plast Surg 2009;25:234-244

29 Serra-Renom JM, Serra-Mestre JM. Periorbital rejuvenation to improve the negative vector with blepharoplasty and fat grafting in the malar area. Ophthal Plast Reconstr Surg 2011;27:442-446

30 Flowers RS. Canthopexy as a routine blepharoplasty component. Clin Plast Surg 1993;20:351-365

31 Jelks GW, Glat PM, Jelks EB, Longaker MT. The inferior retinacular lateral canthoplasty: a new technique. Plast Reconstr Surg 1997;100:1262-1270, discussion 1271-1275

32 Fagien S. Algorithm for canthoplasty: the lateral retinacular suspension: a simplified suture canthopexy. Plast Reconstr Surg 1999;103:2042-2053, discussion 2054-2058

33 Kikkawa DO, Lemke BN, Dortzbach RK. Relations of the superficial musculoaponeurotic system to the orbit and characterization of the orbitomalar ligament. Ophthal Plast Reconstr Surg 1996; $12: 77-88$

34 Mendelson BC, Muzaffar AR, Adams WP Jr. Surgical anatomy of the midcheek and malar mounds. Plast Reconstr Surg 2002;110: 885-896, discussion 897-911

35 Yousif NJ, Sonderman P, Dzwierzynski WW, Larson DL. Anatomic considerations in transconjunctival blepharoplasty. Plast Reconstr Surg 1995;96:1271-1276, discussion 1277-1278

36 de la Plaza R, Arroyo JM. A new technique for the treatment of palpebral bags. Plast Reconstr Surg 1988;81:677-687

37 Muzaffar AR, Mendelson BC, Adams WP Jr. Surgical anatomy of the ligamentous attachments of the lower lid and lateral canthus. Plast Reconstr Surg 2002;110:873-884, discussion 897-911
38 Hwang K, Nam YS, Kim DJ, Han SH. Surgical anatomy of retaining ligaments in the periorbital area. J Craniofac Surg 2008;19: 800-804

39 Lambros V. Observations on periorbital and midface aging. Plast Reconstr Surg 2007;120:1367-1376, discussion 1377

40 Coleman SR. Structural fat grafting: more than a permanent filler. Plast Reconstr Surg 2006;118(3, Suppl):108S-120S

41 Kim EM, Bucky LP. Power of the pinch: pinch lower lid blepharoplasty. Ann Plast Surg 2008;60:532-537

42 Goldberg RA. Transconjunctival orbital fat repositioning: transposition of orbital fat pedicles into a subperiosteal pocket. Plast Reconstr Surg 2000;105:743-748, discussion 749-751

43 Maffi TR, Chang S, Friedland JA. Traditional lower lid blepharoplasty: is additional support necessary? A 30 year review. Plast Reconstr Surg 2011; [Epub ahead of print]

44 Fagien S. Discussion: traditional lower blepharoplasty: is additional support necessary? A 30-year review. Plast Reconstr Surg 2011;128:274-277

45 Garcia RE, McCollough EG. Transcutaneous lower eyelid blepharoplasty with fat excision: a shift-resisting paradigm. Arch Facial Plast Surg 2006;8:374-380

46 Camirand A, Doucet J, Harris J. Anatomy, pathophysiology, and prevention of senile enophthalmia and associated herniated lower eyelid fat pads. Plast Reconstr Surg 1997;100:15351546

47 de la Plaza R, Arroyo JM. A new technique for the treatment of palpebral bags. Plast Reconstr Surg 1988;81:677-687

48 Sadove RC. Transconjunctival septal suture repair for lower lid blepharoplasty. Plast Reconstr Surg 2007;120:521-529

49 Parsa AA, Lye KD, Radcliffe N, Parsa FD. Lower blepharoplasty with capsulopalpebral fascia hernia repair for palpebral bags: a long-term prospective study. Plast Reconstr Surg 2008;121: $1387-1397$

50 Mendelson BC. Herniated fat and the orbital septum of the lower lid. Clin Plast Surg 1993;20:323-330

51 Camirand A. Preserving the orbital fat in lower eyelidplasty. Plast Reconstr Surg 1999;103:737-739

52 McCord CD, Boswell CB, Hester TR. Lateral canthal anchoring. Plast Reconstr Surg 2003;112:222-237, discussion 238-239

53 DiFrancesco LM, Anjema CM, Codner MA, McCord CD, English J. Evaluation of conventional subciliary incision used in blepharoplasty: preoperative and postoperative videography and electromyography findings. Plast Reconstr Surg 2005;116(2): 632-639

54 Patipa M. The evaluation and management of lower eyelid retraction following cosmetic surgery. Plast Reconstr Surg 2000;106: 438-453, discussion 454-459

55 Lelli GJ Jr, Lisman RD. Blepharoplasty complications. Plast Reconstr Surg 2010;125:1007-1017

56 Weinfeld AB, Burke R, Codner MA. The comprehensive management of chemosis following cosmetic lower blepharoplasty. Plast Reconstr Surg 2008;122:579-586 